http://sciforum.net/conference/ece-1

Conference Proceedings Paper - Energies „, Whither Energy Conversion? Present Trends, Current Problems and Realistic Future Solutions"

\title{
Optimizing Wind-Diesel Hybrid Energy Systems Including a Demand Side Management Strategy
}

\section{Susan Krumdieck $^{1, *}$, Jake Frye ${ }^{2}$}

1 Department of Mechanical Engineering, University of Canterbury, Christchurch, New Zealand; E-Mail: susan.krumdieck@canterbury.ac.nz (F.L.)

2 Jake Frye, DNV KEMA Energy \& Sustainability, Boston, MA, USA

* Author to whom correspondence should be addressed; E-Mail: susan.krumdieck@canterbury.ac.nz (F.L.);

Tel.: +64 3364 2987; Fax: +6433642078.

Received: 20 January 2014 / Accepted: 8 March 2014 / Published: 14 March 2014

\begin{abstract}
The New Zealand research station at Scott Base, Antarctica is used as a study of incorporation of wind power generation into an isolated micro-grid powered by diesel generator. The generation plant at Scott Base uses waste heat from the generator to supply heating loads. The Antarctic conditions require gearless wind turbine generators, and the limitations on transport and construction vehicles as well as the demand levels lower than $200 \mathrm{~kW}_{\mathrm{e}}$ dictated the possible size of wind turbine. Energy audit data from the base was used to develop a load model. The current power and heat generation system was simulated using HOMER. The incorporation of wind turbines using local weather data was simulated and an optimal system design determined, based on measure of merit being total fuel consumption. Battery storage is prohibitively expensive. A novel idea of demand side management was explored by effectively storing energy in the form of laundry when excess wind is available and curtailing laundry use when wind speeds are low. Simulations of this deferred load showed increased fuel savings could be gained through demand side participation.
\end{abstract}

Keywords: Remote Power; Wind Power; Hybrid Distributed Generation; Demand Side Management 


\section{Introduction}

While the benefits of added wind power to diesel generator based remote area communities is well known, optimizing wind-diesel systems is problematic. Each remote energy system includes unique energy loading patterns together with a unique and variable wind resource resulting in system design on a case-by-case basis. The design is a balance of wind turbine and diesel generator size that ensures good power quality and a minimum diesel load while maximizing fuel savings. When wind turbines are oversized, an abundance of renewable energy must be dumped in order to maintain the integrity of the hybrid system.

Current equipment optimizing techniques do not consider demand side management (DSM), the potential to shift electricity or heating demand from one time to another, when sizing wind-diesel hybrid energy systems. With DSM, energy that previously would have been dumped could possibly be utilized to supply a load that has been brought forward or held back in time. This paper explains the potential fuel savings that could be realized by introducing DSM techniques to wind-diesel hybrid energy systems and a software tool to model them. Scott Base, New Zealand's Antarctic research station is used as a case study.

\subsection{Background on Scott Base, Antarctica}

Scott Base, an isolated research facility located in the harsh environment of Antarctica is completely reliant on fuel oil (AN8) to meet all of its heat and electricity loads. Antarctic New Zealand, the government body that manages all aspects of Scott Base's existence, has expressed the desire to operate on Antarctica with as small an environmental footprint as possible. This desire includes minimizing green house gas emissions and using renewable energy where possible. The year round wind resource along with the success of wind turbines at Australia's Mawson Station has placed wind power at the top of the list of renewable technologies under consideration at Scott Base.

Antarctica is the driest, coldest, windiest continent on earth. Temperatures can vary from 15 degrees Celsius in summer to -70 degrees Celsius in winter (McGonigal and Woodworth 2002). There are 82 research stations dotting the continent, 45 designed to be occupied year round, operated by 27 different nations (Poland et al. 2002). Scott Base, New Zealand's research station, is located on Pram Point, which is at the end of the Hut Point Peninsula, on Ross Island, at the edge of the Ross Ice Shelf. Each year nearly 100 people spend the summer at Scott Base, while in the winter the population drops to around 15. The base is currently comprised of eight main buildings, each made of sheet steel encased polyurethane foam and connected by all weather corridors. These buildings have a combined floor area of 2340 square meters of which 570 square meters is used as accommodation. The base is maintained at 18 - 20 degrees Celsius indoors (Antarctic New Zealand 1995).

Diesel generators burning approximately 375,000 liters of AN8 each year support the current energy architecture in place at Scott Base. The costs associated with burning AN8 are not only high financially, but environmentally as well. Benefits of increasing the use of renewable energy at Scott Base include cost savings, improved air quality and the reduction in risks associated with fuel transportation. 


\section{Methodology}

Fuel use in remote areas is often at a huge cost to inhabitants who do not have the economic systems in place to absorb higher fuel prices or constraints in the supply chain. Therefore, activities that promote fuel savings are encouraged and often initiated. Investigating the addition of wind power to existing diesel generator based systems is a popular activity. However, current design techniques for wind-diesel hybrid energy systems are not optimal as they do not consider DSM. The methodology followed in this study, which incorporates a DSM load shifting technique designed to optimize the use of wind turbine produced electricity, is as follows:

1) Model the existing diesel based system,

2) Identify appropriate wind turbine technology for Scott Base

3) Build wind-diesel hybrid energy system simulations and

4) Incorporate a DSM modeling tool within the simulations.

The addition of the DSM modeling tool enables the system designer to compare the level of fuel savings that could be expected from a wind-diesel hybrid energy system under a standard structure to those with DSM in place.

\subsection{Existing Diesel Generation System}

Scott base operates on one energy input, Aviation Turbine Fuel (AN8). The combustion of AN8 in Caterpillar generators produces electrical energy, thermal energy and exhaust. Three Caterpillar generators are in operation at Scott Base. All three generator sets are Caterpillar 3406 DI-T Series B electric generators with a maximum rating of $225 \mathrm{~kW}$ electrical and $110 \mathrm{~kW}$ thermal.

Energy use, and its associated carbon footprint, is easily quantifiable at Scott Base as the total amount of AN8 fuel combusted per year. Many fuel saving techniques have been introduced at the base as fuel prices rise and supply ships struggle with ice flows blocking ports. New natural gas appliances, high efficiency lighting and a program to shut down nonessential equipment at night has helped to decrease the average electrical load in recent years. Table 1 shows the decrease in electrical load from 2002 to 2004.

Table 1: Scott Base Electrical Load

\begin{tabular}{rcccccc}
\hline & \multicolumn{2}{c}{$\mathbf{2 0 0 2}$} & $\mathbf{2 0 0 3}$ & \multicolumn{2}{c}{$\mathbf{2 0 0 4}$} \\
\hline Average Electrical Power & 155 & $\mathrm{~kW}$ & 150 & $\mathrm{~kW}$ & 137 & $\mathrm{~kW}$ \\
Minimum Electrical Power & 106 & $\mathrm{~kW}$ & 110 & $\mathrm{~kW}$ & 102 & $\mathrm{~kW}$ \\
Maximum Electrical Power & 183 & $\mathrm{~kW}$ & 183 & $\mathrm{~kW}$ & 172 & $\mathrm{~kW}$ \\
\hline
\end{tabular}

The original Diesel generation system at Scott Base burns approximately 375,000 liters of AN8 to meet its energy demands. Although this is an improvement from over 400,000 liters in 2002, a greater level of fuel savings is possible by targeting how the base produces its energy. With the addition of wind power to the Scott Base energy system fuel use could be cut in half. 


\subsection{Appropriate Wind Technology}

There exists a limited availability of wind turbines in a size range appropriate for Scott Base that can withstand the extreme weather conditions of the area. When considering the addition of a wind turbine to a remote area energy system, medium scale turbines are typically considered. However, most of the research and development in wind turbine design in recent years has not focused on medium scale machines. Choices become even more limited when siting turbines in extreme climates. Fortunately, there are two manufacturers who recognize the need for medium scale turbines with characteristics that lend themselves to cold climates. These characteristics include greater nacelle insulation, blade heating and the limited use of oil by removing the gearbox. Turbine specifications for the NorthWind 100 and Enercon E33 are detailed in Figure 1.

Figure 1. Medium Scale Cold Climate Turbine Specifications

\begin{tabular}{|c|c|c|c|c|}
\hline \multicolumn{5}{|c|}{ NorthWind NW 100/19 Wind Turbine } \\
\hline Nominal Rated Power & 100 & KW & Drive Train: & Variable Speed Direct Drive \\
\hline Nominal Wind Speed & 15 & $\mathrm{~m} / \mathrm{s}$ & Generator: & Salient Pole Synchronous \\
\hline Cut-In Speed & 4 & $\mathrm{~m} / \mathrm{s}$ & Speed Range: & 45-69 RPM \\
\hline Cut-Out Speed & 25 & $\mathrm{~m} / \mathrm{s}$ & & Active Yaw Control \\
\hline Diameter & 19.1 & $\mathrm{~m} / \mathrm{s}$ & Braking: & Mechanical \& Electrodynamic \\
\hline Swept Area & 284 & $\mathrm{~m} 2$ & & \\
\hline Hub Height & 25,32 & $\mathrm{~m}$ & & \\
\hline \multicolumn{5}{|l|}{ Enercon E-33 Wind Turbine } \\
\hline Nominal Rated Power & 330 & KW & Drive Train: & Enercon Direct Drive \\
\hline Nominal Wind Speed & 12 & $\mathrm{~m} / \mathrm{s}$ & Generator: & Synchronous Annular \\
\hline Cut-In Speed & 2.5 & $\mathrm{~m} / \mathrm{s}$ & Speed Range: & 18-45 RPM \\
\hline Cut-Out Speed & $28-34$ & $\mathrm{~m} / \mathrm{s}$ & & Active Yaw Control \\
\hline Diameter & 33.4 & $\mathrm{~m} / \mathrm{s}$ & Braking: & Rotor brake \& lock with 3 inde \\
\hline Swept Area & 876 & $\mathrm{~m} 2$ & & -pendent blade pitching systems \\
\hline Hub Height & $34-50$ & $\mathrm{~m}$ & & \\
\hline
\end{tabular}

\subsection{Model Simulation}

The Hybrid Optimization Model Energy Resource, otherwise known as HOMER, is a computer model tailored for the simulation of hybrid power systems. HOMER was developed by the National Renewable Energy Laboratory in Golden, Colorado. HOMER is a broad-based optimization tool that is best used to determine basic system design (National Renewable Energy Laboratory 2005). With 
inputs such as community loads and wind speed data, multiple system components can be evaluated in order to determine the most appropriate system configuration. HOMER uses an hourly time-step and is considered the state of the art to determine optimal system configurations in the field of hybrid system simulation (Baring-Gould et al. 2002; Lundsager et al. 2001).

The creation of each proposed wind-diesel hybrid energy system configuration is based on two identified wind turbines suitable for Antarctic installation. Utilizing the two identified turbines, five possible wind-diesel hybrid energy system configurations are modeled utilizing the HOMER software.

- Existing diesel generator sets with 1 Northwind 100 turbine

- Existing diesel generator sets with 2 Northwind 100 turbines

- Existing diesel generator sets with 3 Northwind 100 turbines

- Existing diesel generator sets with 1 Enercon E33 turbine

- Existing diesel generator sets with 2 Enercon E33 turbines

For each proposed system configuration there are multiple simulation structures possible. The simulation structures represent how the architecture of the energy system is built. Different protocols on how power supply meets demand can result in different levels of fuel savings. The primary analysis is based on a standard simulation structure for each model. A demand side management structure is also modeled which utilizes a Matlab algorithm in coordination with the HOMER modeling software to represent load shifting. Therefore, the results of ten different theoretical wind-diesel hybrid energy systems for Scott Base are reported. Simulation structure definitions are as follows:

Standard Structure: if a wind turbine is operating within the wind-diesel system, its power supply is utilized to meet the electrical load. Any remaining electrical load that is not supplied by wind generated power is supplied by electricity produced by the diesel generator sets. In generating power to meet any left over Scott Base electrical loads, the diesel generator sets also produce thermal energy. This recovered heat is applied to the Scott Base thermal load. Often the recovered thermal energy from the diesel generator is not sufficient to meet the base thermal load and power from the boiler(s) is necessary to supply the remaining thermal load. This is the typical way in which wind-diesel hybrid energy systems are structured.

Demand Side Management Structure: this simulation structure includes a novel demand side management technique applied to a base load. In this case the Scott Base laundry facilities load has been identified as suitable for modification as it is nonessential and time-flexible. The new demand side management technique moves the laundry facility load forward in time to when wind generated electricity may be abundant. By pausing the laundry facility load for a number of hours, wind generated electricity may be able to supply a greater percentage of the electrical load. A limit to how long the laundry load can be shifted is established. In this way the laundry service is always provided, however, that service is provided within a set of time limits. This technique is introduced to better coordinate any potential wind turbines with the electrical demand of Scott Base.

Model inputs include Scott Base electrical and thermal load data recorded by base personnel and wind resource data collected by Meridian Energy in the vicinity of a possible turbine site for the 2004 
calendar year. Specifications of the existing diesel generators, boilers and potential wind turbines are provided by Scott Base engineers and manufacturers.

\subsection{Demand Side Management HOMER Extension}

In the case of Scott Base, a specific load has been identified as appropriate for load shifting. This load is the laundry facilities. The possibility of a load shift must be evaluated at the same time-step as that of the HOMER model. Therefore, for each hour of a year the laundry facility load must be compared to the wind turbine(s) electrical production. To compare the laundry facility load with the wind turbine(s) electrical production at each time-step, a Matlab algorithm is created and used as an add-on to the HOMER model. The Matlab algorithm structure is outlined in Figure 2.

Figure 2. Demand Side Management Modelling Tool Structure

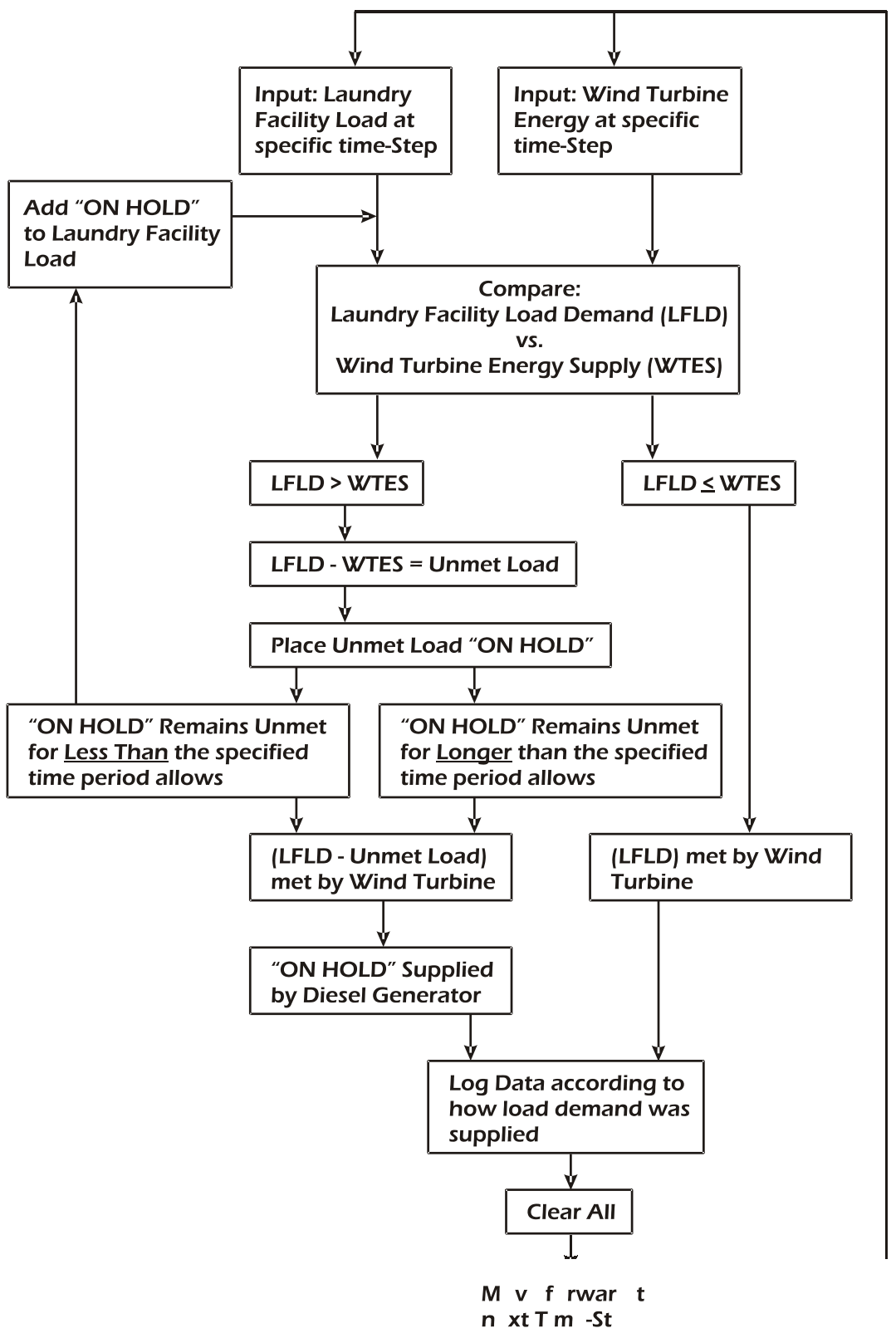


The incorporation of time flexibility into the laundry facility load represents the demand side management technique of load shifting. At each hour in the hybrid system simulation an algorithm is run to determine any possible extra fuel savings via the load shift. At each hour if there is enough excess electricity to meet the laundry load, it is supplied. If there does not exist enough excess electricity to meet the laundry load, it is postponed and not supplied by the generator sets. The following hour sees either a new laundry load or one that incorporates the demand of the previous hour according to the previous hour's supply. This logic continues unless the laundry facility load remains unmet for a continuous number of hours that correspond to the identified time period. If the time period is reached the complete laundry facility load is supplied with power from the generator sets. In this manner, the service that the laundry facility provides is made available not at all times but over an identified period of time.

\section{Results}

Two sets of results are outlined in the following sections. The first set, Standard Structure, details the potential fuel savings for each of five wind-diesel hybrid system models with varying levels of installed wind power capacity (from $100 \mathrm{~kW}$ in Model \#2 to $660 \mathrm{~kW}$ in Model \#6). The second set, Demand Side Management Structure, details the additional fuel savings that could be achieved by incorporating a novel DSM technique to the Scott Base laundry facilities load.

\subsection{Standard Hybrid Structure}

Simulated over the course of one full year, the following results represent the predicted performance of the five proposed wind-diesel hybrid energy system models. Using the standard simulation structure, any wind generated electricity is supplied to the Scott Base electrical load with the generator sets supplying any unmet demand. A 30\% minimum diesel load is enforced to ensure the generator set's life-spans are not adversely effected by low loading. After supplying the electrical load, excess wind energy is applied to the base thermal load with the remaining thermal demand being supplied by recovered heat from the generator sets and the base boilers. In each model the Scott Base electrical and thermal demand are met $100 \%$ with a combination of the diesel generators, boilers and wind turbines. Any remaining wind generated electricity in excess of the electrical and thermal demand is considered surplus. Results of each model simulation are detailed in Error! Reference source not found. Model \#1 is the benchmark that all other simulations are measure against, being the simulation of the existing Scott Base energy system.

Predicted fuel use for all models follows an expected pattern with only one exception, as wind power capacity increases, predicted generator and boiler fuel use decreases. The exception is for Model \#2 where predicted boiler fuel use increases with the addition of a $100 \mathrm{~kW}$ turbine. This highlights the potential problem of adding wind power to an energy system partly dependent on recovered waste heat to supply a thermal load. However, Model \#3, with $200 \mathrm{~kW}$ of wind power capacity, predicts a decrease in boiler fuel use. Therefore, unless Scott Base is comfortable with an increased dependence on the boilers, more than $100 \mathrm{~kW}$ of installed wind capacity is necessary. 
Table 2. Standard Structure Simulation Results

\begin{tabular}{|c|c|c|c|c|c|c|}
\hline \multirow{3}{*}{$\begin{array}{r}\text { Model \#1 } \\
\text { Total: }\end{array}$} & \multirow{3}{*}{$\begin{array}{l}\text { Benchmark } \\
392592 \text { L }\end{array}$} & \multirow{2}{*}{\multicolumn{3}{|c|}{$\begin{array}{c}\text { Standard System Structure } \\
\text { Litres of Fuel Consumed }\end{array}$}} & \multirow{3}{*}{$\begin{array}{c}\text { Predicted } \\
\text { Fuel Savings } \\
\text { Per Year (L) }\end{array}$} & \multirow{3}{*}{$\begin{array}{c}\text { Pay Back } \\
\text { Period } \\
\text { (Yrs.) }\end{array}$} \\
\hline & & & & & & \\
\hline & & Total & Generator & Boiler & & \\
\hline Model \#2 & $\begin{array}{l}\text { One Northwind } 100 \mathrm{~kW} \\
\text { Wind Turbine }\end{array}$ & 331151 & 274731 & 56420 & 61441 & 13.5 \\
\hline Model \#3 & $\begin{array}{l}\text { Two Northwind 100kW } \\
\text { Wind Turbines }\end{array}$ & 295556 & 255028 & 40528 & 97036 & 17.1 \\
\hline Model \#4 & $\begin{array}{l}\text { Three Northwind 100kW } \\
\text { Wind Turbines }\end{array}$ & 270064 & 237216 & 32848 & 122528 & 20.3 \\
\hline Model \#5 & $\begin{array}{l}\text { One Enercon 330kW } \\
\text { Wind Turbine }\end{array}$ & 219907 & 191750 & 28157 & 172685 & 7.9 \\
\hline Model \#6 & $\begin{array}{l}\text { Two Enercon 330kW } \\
\text { Wind Turbines }\end{array}$ & 154766 & 133924 & 20842 & 237826 & 11.4 \\
\hline
\end{tabular}

\subsection{Demand Side Management Structure}

The demand side management simulation structure is evaluated to determine potential fuel savings if a novel laundry facilities load shifting technique were implemented at Scott Base. This novel technique is a theoretical automation of the laundry facilities at the base. The key aspect of this DSM technique is that the laundry service would be time-flexible; thus if wind generated electricity was not available then the laundry service is delayed. This load management might be possible with a signal device for users to obey or automatically initiated with a ripple control style switch. By coordinating available wind power with the laundry load, surplus wind power, which may have otherwise been unused, may be applied to a time flexible service such as the base laundry.

Each proposed model is evaluated for load delay periods from zero hours to 48 hours. In all cases, if the laundry facility load is not met by wind-generated electricity in the specified period of time, it is met with the generators. In this way, the laundry service is always provided within the specified time period. The additional fuel savings predicted by the model simulations including DSM of the laundry facilities load are detailed in Table 2. Graphical representations of the additional fuel savings predicted for each model based on the addition of the DSM tool are shown in Figure 3.

Table 3. Demand Side Management Structure Simulation Results

\begin{tabular}{|llcccc|}
\hline \multirow{2}{*}{ All values in liters of AN8 fuel } & \multicolumn{4}{c|}{ Allowable Laundry Facility Load Delay } \\
\cline { 3 - 6 } \multicolumn{1}{c|}{} & 3 hours & 6 hours & 12 hours & 24 hours \\
\hline Model \#2 & One Northwind 100kW Wind Turbine & 54 & 85 & 139 & 166 \\
\hline Model \#3 & Two Northwind 100kW Wind Turbines & 286 & 424 & 793 & 1204 \\
\hline Model \#4 & Three Northwind 100kW Wind Turbines & 292 & 520 & 727 & 1177 \\
\hline Model \#5 & One Enercon 330kW Wind Turbine & 266 & 499 & 800 & 1227 \\
\hline Model \#6 & Two Enercon 330kW Wind Turbines & 295 & 514 & 831 & 1110 \\
\hline
\end{tabular}


Figure 3. Predicted Fuel Savings with Laundry Facilities DSM and 1 NorthWind 100kW Turbine

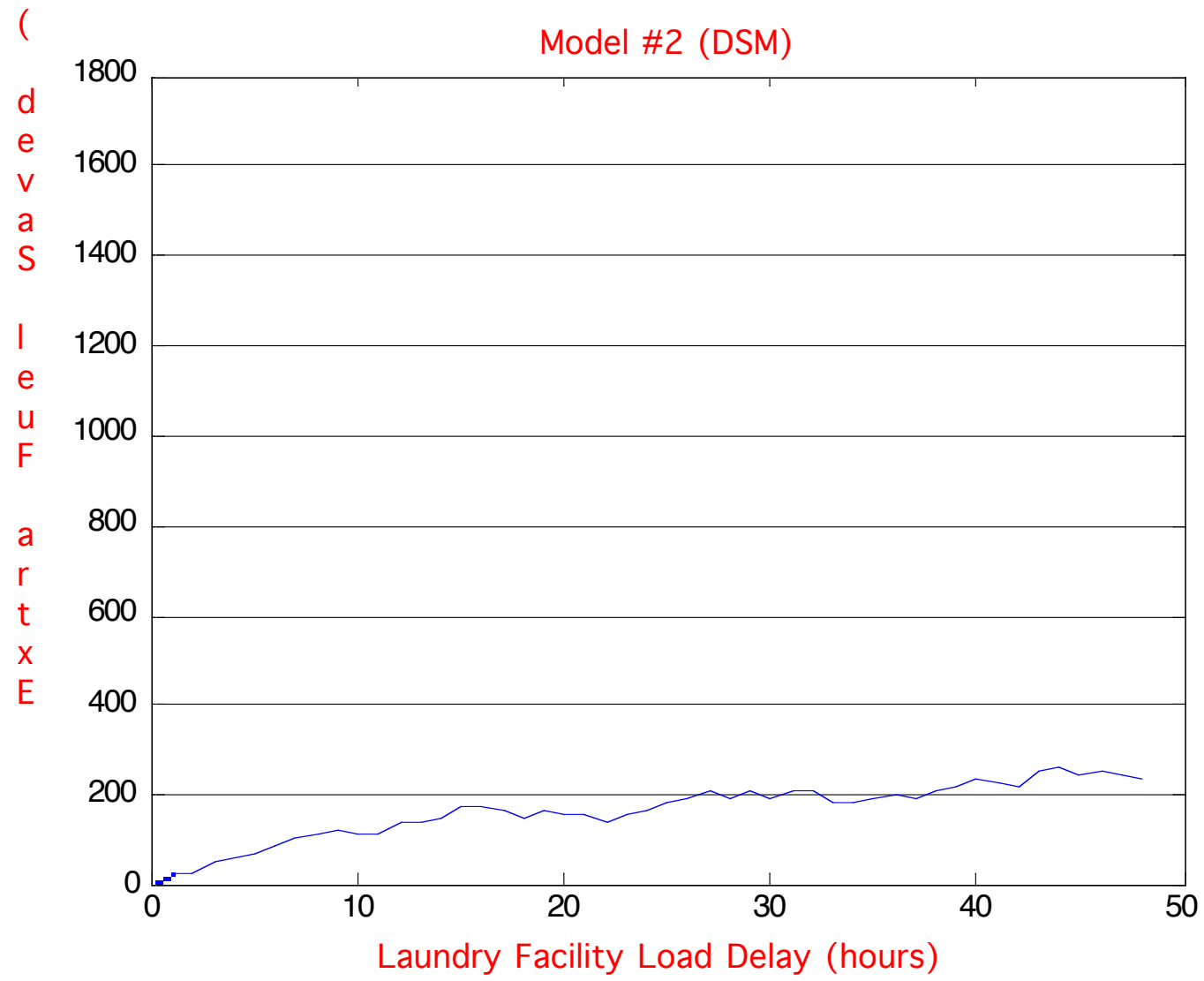

Figure 4. Predicted Fuel Savings with Laundry Facilities DSM and 2 NorthWind 100kW Turbines.

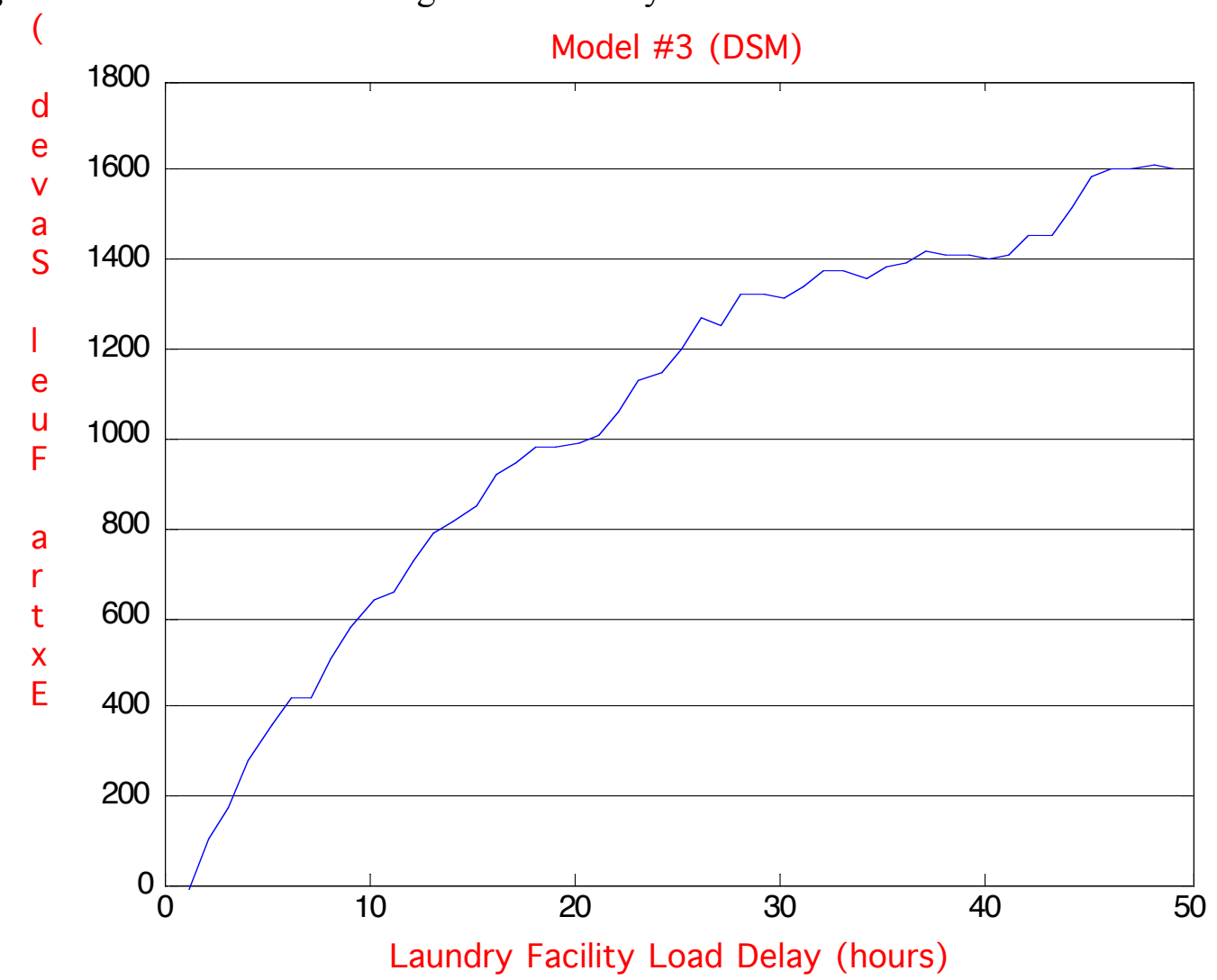


Figure 5. Predicted Fuel Savings with Laundry Facilities DSM and 3 NorthWind 100kW Turbines.

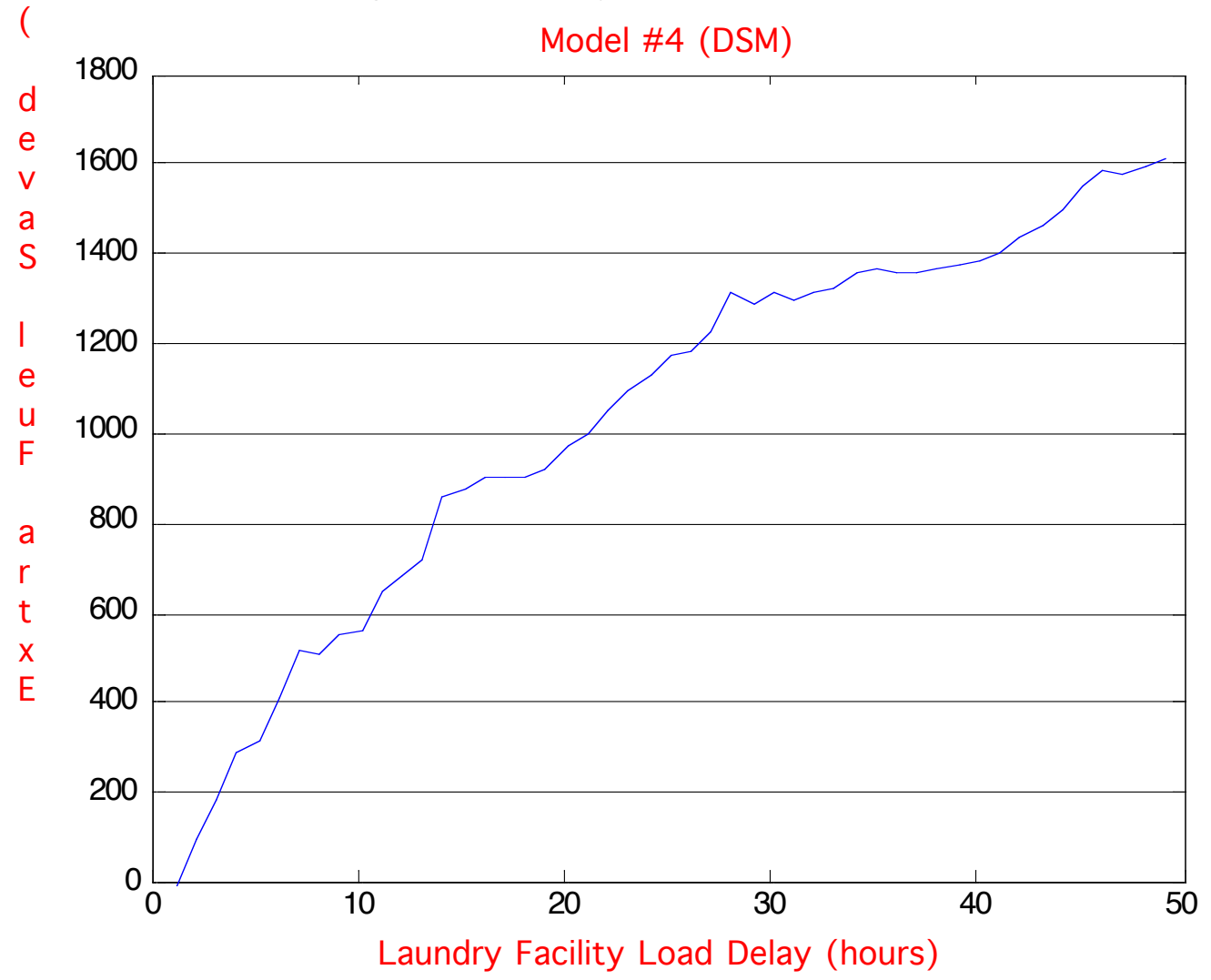

Figure 6. Predicted Fuel Savings with Laundry Facilities DSM and 1 Enercon 330kW Turbine

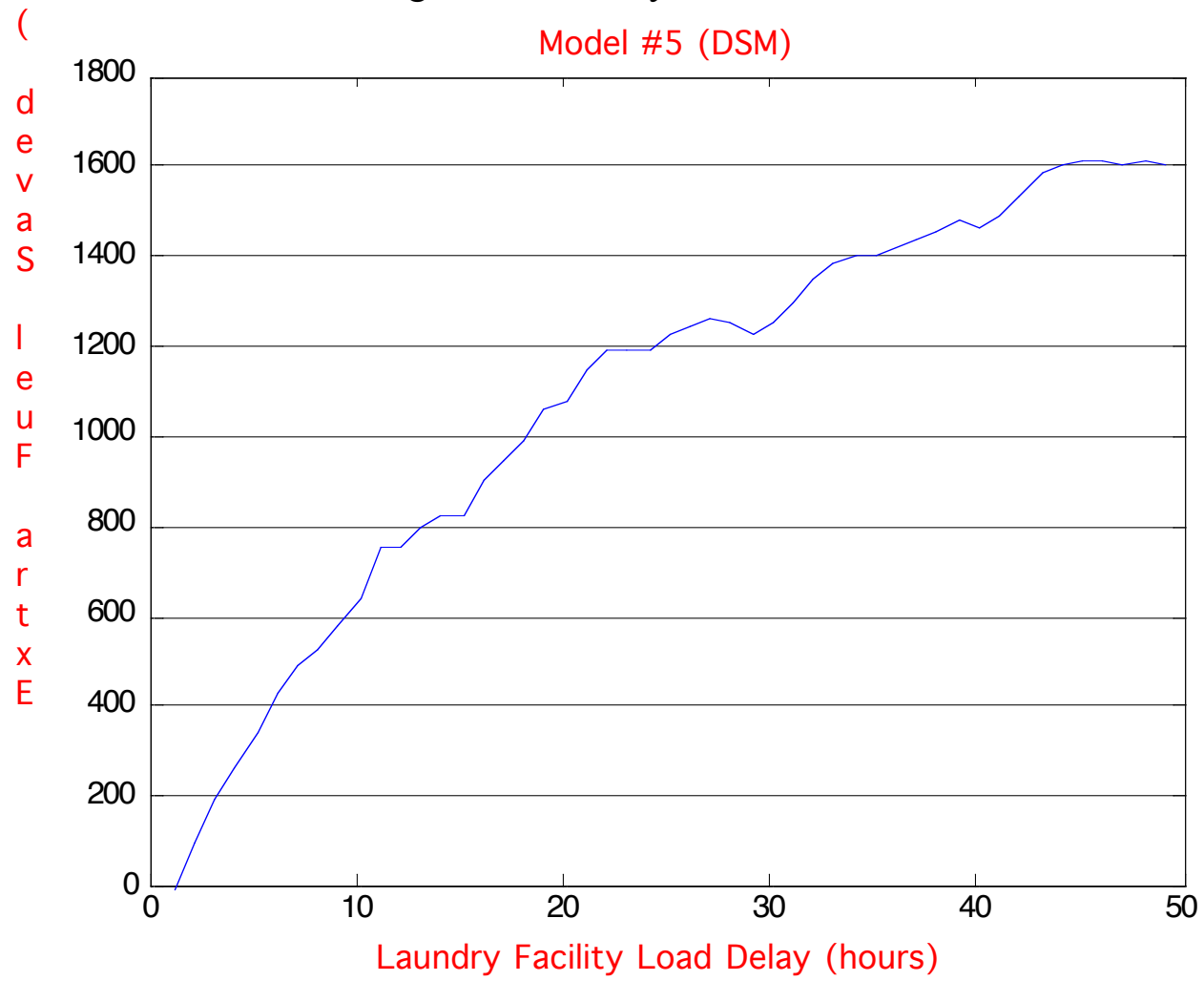


Figure 7. Predicted Fuel Savings with Laundry Facilities DSM and 2 Enercon 330kW Turbines

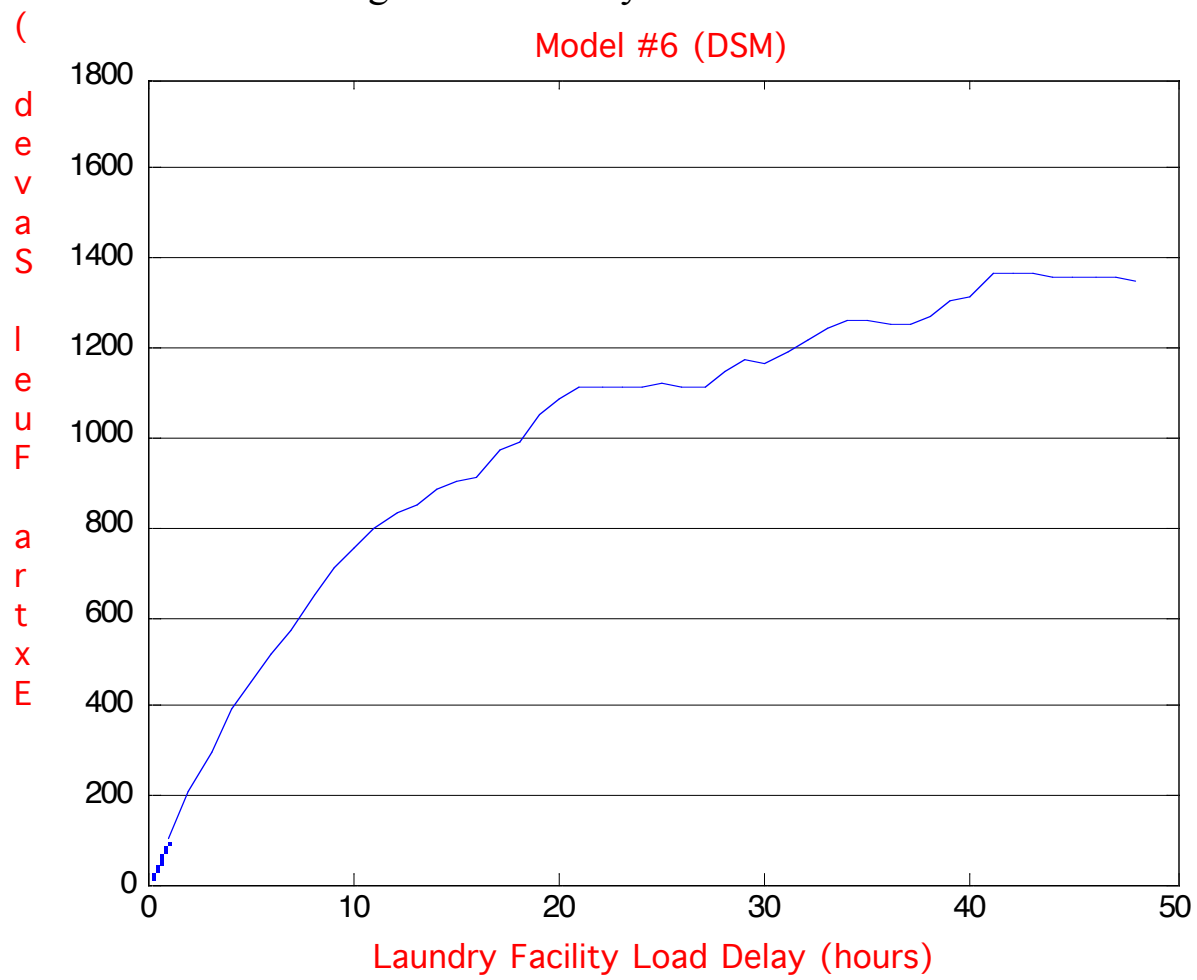

Figure 3 through Figure 7 suggest a minimum installed wind capacity where significant additional fuel savings are possible. It is clear that with only $100 \mathrm{~kW}$ of installed wind power (Model \#2), approximately 200 additional liters per year could be saved with a laundry load delay of 48 hours. While with $200 \mathrm{~kW}$ of installed wind power (Model \#3), approximately 1600 liters of fuel could be saved with a similar laundry load delay. The second characteristic shown in the figures above is a suggested limit on the amount of additional fuel savings possible. The flattening of the curve in all model graphs indicates that 1600 liters is the maximum amount of savings regardless of the period of time flexibility.

\section{Conclusions}

The importance of modeling energy systems is increased when remote area communities are concerned. The costs associated with shipping into isolated areas and the seasonal schedules for potential construction leave the system designer with little room for modification. A novel demand side management technique is developed by coordinating available wind power to the Scott Base laundry facility load. Results show that extra fuel savings are possible using this technique although relatively small. The savings increase with an increase in allowable time delay to a maximum level. 


\section{Acknowledgments}

Contributions from Jonathan Leitch, Antarctica New Zealand, included discussions, descriptions of the base, and measurements of power usage used to develop the load model. Wind measurement data used for simulation was provided without charge by Meridian Energy.

\section{Conflicts of Interest}

The authors declare no conflict of interest.

\section{References and Notes}

1. McGonigal, D., and Woodworth, L. (2002). Antarctica: the blue continent, Random House New Zealand, Auckland.

2. Antarctic New Zealand. (1995). "Scott Base Operations Manual." Christchurch.

3. National Renewable Energy Laboratory. (2005). "Getting Started Guide for HOMER Version 2.1." National Renewable Energy Laboratory, Golden, Colorado.

4. Baring-Gould, E. I., Flowers, L., Lundsager, P., Mott, L., Shirazi, M., and Zimmermann, J., "Worldwide Status of Wind-Diesel Applications." DOE/AWEA/CanWEA wind-diesel conference.

5. Lundsager, P. (1991). "RISO: WDILOG - A Logistic Wind-Diesel Simulation Model Description and Users Guide." Riso National Laboratory, Denmark.

(C) 2014 by the authors; licensee MDPI, Basel, Switzerland. This article is an open access article distributed under the terms and conditions of the Creative Commons Attribution license (http://creativecommons.org/licenses/by/3.0/). 